\title{
A Doctorate Degree Program in Information Systems of a Kind
}

\author{
Frederick Kohun \\ Robert Morris University, \\ Pittsburg, PA, USA
}

\author{
Azad Ali \\ Butler County Community \\ College, Butler, PA, USA
}

kohun@rmu.edu

\author{
azad.ali@bc3.edu
}

\begin{abstract}
This paper discusses the design characteristics of a doctoral program in information systems at a university located in Western Pennsylvania. The program design includes unique characteristics that are intended to minimize the attrition rate among the students enrolled. The paper begins by discussing baseline statistics and reasons for attrition rates in doctoral programs. The focus thereafter is an overview of computer related doctoral programs that offer doctoral degrees in information systems. It concludes with a detailed description of the specific design attributes of the Doctor of Science program in Information Systems and Communications at Robert Morris University (RMU).
\end{abstract}

Keywords: Doctorate of Science, Information System Doctorates, IS Programs, Pennsylvania IS Doctorate Programs, Computer Information Systems

\section{Introduction}

Attrition rates among doctoral students have been a problem for a long time. Numerous studies have been conducted to address the issue of retention among doctoral students, and as a result, the literature lists various suggestions that were aimed to minimize the number of students leaving the doctoral programs prior to completion. As a result, doctoral programs are implementing policies in order to revamp their programs to come to terms with the issue of retention.

This paper explains how one doctoral program from its inception has addressed the issue of retention. The Doctor of Science program in Information Systems and Communications at Robert Morris University (Located in Western Pennsylvania) began in 1999. Through deliberate design characteristics and attributes, the university was able to graduate $90 \%$ of their students enrolled in the three year program on time.

The paper begins by presenting statistics regarding attrition rates and the common cited reasons for early exit among doctoral students. Focus then shifts to the discussion of the common characteristics of doctoral programs in the computer/information systems field. To narrow the focus of this study and to provide a baseline of comparison, this paper does a brief review of the com-

Material published as part of this journal, either on-line or in print, is copyrighted by Informing Science. Permission to make digital or paper copy of part or all of these works for personal or classroom use is granted without fee provided that the copies are not made or distributed for profit or commercial advantage AND that copies 1) bear this notice in full and 2) give the full citation on the first page. It is permissible to abstract these works so long as credit is given. To copy in all other cases or to republish or to post on a server or to redistribute to lists requires specific permission from the publisher at Publisher@InformingScience.org puter/information systems programs in the Commonwealth of Pennsylvania. Lastly, the discussion is directed to the unique characteristics of the doctoral program and its effectiveness in retention and graduation rates at Robert Morris University (RMU). 


\section{Doctoral Attrition - Numbers and Reasons}

The high attrition rate among doctoral students is not a new problem. The studies that are conducted for this purpose are numerous. Some of the studies focus on the problems that cause attrition, while others go into detail about the affect that attrition has on students, the university, and society in general (Lovitts, 2001). Moreover, various surveys and annual statistics are produced nationally to address the severity of this problem (National Center for Educational Statistics [NCES], 2004).

In one study, the author estimated that about half of all Ph.D. candidates drop out before completion (Powers, 2004). While this study did not clearly define the meaning of "Doctoral Candidates" (after completing the course work or not), nevertheless, a drop out rate of $50 \%$ is significant. Another study by Arizona State University surveyed a group of doctoral students to ascertain the percentage of completion after each year. This study tabulated results year by year by listing the percentage of original students who completed the degree. It revealed that a substantial number (about $8 \%$ ) of the students who started the doctoral program did not complete it after 9 years (Arizona State University, 2003). Although these two studies cite percentages (50\% and $8 \%)$ that are seemingly different, the second number ( $8 \%$ ) suggests a longer time period of study may reduce attrition.

In another comprehensive study conducted for this purpose, the author interviewed students who completed their respective doctoral programs and students who did not complete them. The same author compiled numerous tables regarding attrition rates from a sample of over 800 doctoral students. For example, one table showed that attrition rate is about $33 \%$ for departments in rural universities and 68\% for universities at urban universities (Lovitts, 2001).

The Digest of Education Statistics for 2002 presents a dire picture about the percentage of students who start high school and ended up being enrolled in the doctoral programs after 10 years. It listed that only .2\% (2 in a thousand) of male students and .1\% ( 1 in a thousand) for female students who started in high school ended up enrolling in a doctoral program (NCES, 2004). So, while only one in a thousand of the population enrolls in a doctoral program, still fewer graduate from such programs.

The above studies cited various reasons for such high attrition rates that extend well beyond student lack of interest or the decision fostered by student personal issues. Among the other reasons that were cited by the studies include:

1- Lack of structure or enforcement mechanisms by the program (Lovitts \& Nelson, 2005).

2- Strong focus on theory throughout the programs in general and during the dissertation process in particular (Bourner, Bowden, \& Laing, 2001).

3- Feeling of isolation or lack of connection among the peers of the students in the program or among the students and the faculty and administration in the program (Lovitts, 2001).

\section{Computer Related Doctoral Degree Programs}

The doctoral programs in the computer technology field share two specific characteristics. First, because the computer field is changing rapidly, frequent change in the content of such programs is commonplace. Second, because the computer field is a relatively new field, its identity and common body of knowledge is still evolving. As a result, there is significant diversity and variety in the programs under the category of computer and information systems. Each program takes on a different "look and feel" such that no two programs are alike.

The Peterson's guide for graduate programs lists different graduate programs across the US ("Graduate \& Professional Programs: An Overview," 2004). This guide categorizes programs by 
subjects of study. There are seven categories that include computer related fields. Overall, 440 doctoral degree programs are listed in the Peterson's guide under different categories of computer studies. The able lists the various fields of computer study programs and the number of universities offering doctoral program in each of the categories:

Table 1 - Categories of Doctoral Programs in Computer Related Fields

\begin{tabular}{|l|c|}
\hline \multicolumn{1}{|c|}{ Category Name of Doctoral Program } & Number of Programs Across the US \\
\hline Computer Education & 10 \\
\hline Computer Engineering & 121 \\
\hline Computer Science & 170 \\
\hline Information Science & 45 \\
\hline Information Studies & 23 \\
\hline Management Information Systems & 51 \\
\hline Management of Technology & 22 \\
\hline Total number of schools offering doctorate degrees & 442 \\
\hline
\end{tabular}

The list above includes programs that are repeated and referenced more than once. In other words, the same program could be listed under more than one category. Thus the actual number of doctoral programs in each category may be less than is indicated in the table. Nevertheless, a listing like this provides context for the diversity, variety, and number of doctoral programs listed categorically.

\section{IS Doctoral Programs in Pennsylvania}

The Peterson's guide to graduate programs lists the doctoral programs at Robert Morris University under two different categories ("Graduate Programs in Business," 2004). First it lists it under the Information Science category and second it lists it under Management Information Systems category. Based on this classification, this paper concentrates on the doctoral programs in these two categories.

In order to show some common characteristics among programs that offer doctorate degree in information systems, this paper selected only the universities that offer such degrees in the Commonwealth of Pennsylvania. There are eight universities that offer doctoral programs in the areas of information science and management information systems: Carnegie Mellon University, Drexel University, Lehigh University, Pennsylvania State University, Temple University, University of Pennsylvania, University of Pittsburgh and Robert Morris University ("Graduate Programs in Business," 2004). The remainder of this section lists a few of the characteristics of a sample of seven programs in Pennsylvania (information taken directly from the respective university website). The subsequent section then discusses the doctoral program at Robert Morris University.

\section{Carnegie Mellon University}

The Tepper School of Business at Carnegie Mellon University offers a Ph.D. degree in Industrial Administration. The program requires that degree candidates complete to the satisfaction of the faculty: 
1- An approved program of study in the major area.

2- Two research papers, one each at the end of the first and second program years

3- The third semester qualifying examination

4- Completion of 18 units of credit for minor area courses

5- A doctoral dissertation (a written thesis representing original research, approved by an assigned committee of the faculty, and defended in public).

Fulfillment of the doctoral program requires that the student complete between 136 and 162 course units. The exact course-unit requirement is dependent upon the student's prior preparation in information systems and business (Carnegie-Mellon University, 2004).

\section{Drexel University}

The College of Information Science and Technology at Drexel University offers a Ph.D. program which brings together both people and knowledge from multiple backgrounds and disciplines. There is no prescribed length of time for the program. It could be completed by as few as three years and can take up to five or more (depending on the time a student can devote to it). A committee of three program advisors (PAs) will oversee each student's course planning and progress. The PAs may also act as research mentors. Their main task is to develop a plan of study with the students. The plan consists of two parts: first, the discursive program of study; and, second, the official plan of study.

The degree requires a minimum of 60 credits beyond an applicable M.S.degree with at least three consecutive terms of full time resident study (Drexel University, 2004).

\section{Lehigh University}

The Peterson's Guide to graduate programs ("Graduate Programs in Business," 2004) lists a doctoral program for Lehigh University under the category of Information Studies. However, we researched the web site of the same university and did not find a doctorate program in either Information Science or Management Information Systems. The closest degrees to the two above categories that we found on Lehigh University web site are both in Computer Science: one in Computer Science and Engineering and the second in Electrical Engineering and Computer Science. We decided to concentrate on the first one "computer science and engineering".

The P.C. Rossin College of Engineering \& Applied Science at Lehigh University offers a Ph.D. program in Computer Science. It conducts cutting-edge research in a variety of key fields and encourages students to take an active role in the rapid growth of its graduate program. Some of the areas that are covered under this program include:

1- Computer systems engineering, including computer arithmetic, computer architecture and computer vision.

2- Intelligence software systems engineering, including networking and network caching, software architecture and computer vision.

3- Information Systems Engineering, including distributed data indexing, databases and virtual environments (Lehigh University, 2004).

\section{Pennsylvania State University}

The School of Information Sciences and Technology at Penn State University offers a Ph.D. program in the information sciences and technology for individuals seeking to become dynamic 
leaders in research and teaching who are focused on the problems and challenges of the digitalbased, global-economy.

The course requirement includes both a core and electives. The core of the IST Ph.D. program is composed of four courses and a required colloquium. These courses represent the paired relationships of the three central constructs in the information sciences - information, user, technology and the integration of all three. Collectively, these courses will help students with a rich conceptualization of the field (Pennsylvania State University, 2004).

\section{Temple University}

The Graduate School at Temple University offers a doctorate (Ph.D.) program in Computer and Information Sciences. The concentration area is in information systems. The students are required to complete the degree program through classes offered after 4:30 p.m. The course requirements include theory area topics, system area topics and tracks specific area. Additional requirements include taking the qualifier examination that tests the student on the fundamentals of computer and information sciences and the basic body of knowledge in a track. It consists of written exam on theory and algorithms, systems, and track specific materials. Writing skills are also formally assessed. A student must pass a two hours essay exam given once a year, normally a week after the qualifier exam (Temple University, 2004).

\section{University of Pennsylvania}

The department of Computer and Information Science offers a doctorate of philosophy (Ph.D.) degree in the Penn School of Engineering and Applied Science. The program is intended for candidates with undergraduate training in one of the modern information processing fields. $\mathrm{PhD}$ students must take four seminar courses (600-level or above) during their studies at Penn-two courses related to the dissertation research area, and two in an unrelated area. Two half-credit seminars may be counted as one course for purposes of this requirement. Doctoral students must spend one year in residence (defined as two consecutive semesters of full time enrollment) at University of Pennsylvania (University of Pennsylvania, 2004).

\section{University of Pittsburgh}

The department of Library \& Information Science at the University of Pittsburgh offers a doctorate of philosophy (Ph.D.) degree. Students are required to complete 54 credit hours beyond their master degree in order to complete the program. The program prepares the students to advanced work in research, teaching and administration. The primary purpose of the program is to develop and understanding of library and information science beyond the master degree with particular emphasis on the conduct of original research, the productivity and generalizability of research findings and the contribution of such findings to the public. The program requires 54 credits with a minimum of 36 seminar credits beyond the master's degree and 18 dissertation credits (University of Pittsburgh, 2004).

\section{The Doctoral Program at Robert Morris University}

The Doctor of Science in Information Systems and Communications degree at Robert Morris University (RMU) started in 1999. The first group of students graduated from this program in May of 2002. The second group started in 2000 and completed their degrees in 2003 and the third cohort graduate in 2004. This program was able to achieve a higher degree of graduation that the national average. Table 2 below shows the completion rate for each of the three cohorts that finished the program. 
The goal of this "lock step" three year program as stated in the university materials is to "address the expanding needs of professionals, who manage information resources, solve information, communication, and technology related problems in businesses and other organizations, education and/or train others in fields to the application of information systems and communications" (Robert Morris University, 2004).

Table 2 - Evidence of Successful Completion Rate at RMU

\begin{tabular}{|c|c|c|c|c|}
\hline Cohort Name & Start Semester & $\begin{array}{c}\text { \# Students In } \\
\text { Cohort }\end{array}$ & $\begin{array}{c}\text { Number Completed } \\
\text { after 3 Years }\end{array}$ & $\begin{array}{c}\text { Percentage Com- } \\
\text { pletion Rate }\end{array}$ \\
\hline Cohort 1 & Fall 1999 & 12 & 12 & $100 \%$ \\
\hline Cohort 2 & Fall 2000 & 15 & 12 & $80 \%$ \\
\hline Cohort 3 & Fall 2001 & 17 & 15 & $88.2 \%$ \\
\hline
\end{tabular}

The remainder of this section presents characteristics that are unique to the program that made it A Doctorate Degree Program in Information Systems of a Kind.

\section{Doctorate of Science - D.Sc.}

The degree that is offered in this regard is the Doctorate of Science (D.Sc.). This is contrast to the better known doctorate of Philosophy (Ph.D.). While the terminologies between the two degrees are seemingly different, the differences between the two degrees are best described as "subtle" with the primary difference lying in the research emphasis. Even the definition of the two degrees does not reveal a clear cut about the difference between the two degrees. The BrainyEncyclopeida defines Sc.D. or D.Sc. as "Abbreviation of the Latin Scientific Doctor. It is an academic degree on par with the wider known Ph.D. The D.Sc. is awarded predominantly in engineering sciences, whereas classical sciences seem to prefer the Ph.D." (NationMaster, 2004). The same web site defines Ph.D. as "an abbreviation of the Latin Philosophical Doctor .... Was originally a degree granted to a learned individual who had achieved the award and who had demonstrated a long and productive career in the field of philosophy" (NationMaster, 2004). Plus, the US Department of Education and the National Science Foundation recognize both research doctorates (NationMaster, 2004).

While studies have attempted to explain the difference between the two degrees, it seems that the difference between the two degrees does not stem from the overall process of completing the degree, the number of courses taken or the emphasis on research. To the contrary, it seems that both degrees place strong emphasis on research and a final research project/dissertation.

Additional studies found subtle differences between the two degrees mainly in three areas: 1) in the domain of research topic, 2) the research type, and 3) the research focus. The Studies of Higher Education Journal grouped the D.Sc. with professional doctorates acknowledging that the difference between what is called traditional doctorates (or Ph.D.) and professional doctorates remain a "blur" at best. It described the emphasis of both degrees on course work and on research. While the journal got into a long explanation of the difference between the two degrees in terms of research topics, it noted that "while the PhD student can, at least in theory, research any topic at all within the field of study, the candidate for a professional doctorate is usually expected to undertake research at making contribution to the knowledge of professional practice" (Bourner, et al., 2001). 
Regarding the research type, the above study explained that most Ph.D. research would be an "original investigation undertaken to gain knowledge and understanding but not directly towards any practical aim or application". While in professional doctorate "an original investigation undertaken to gain new knowledge and practical aims and objectives, which a reasonable description of the research required for most of the professional doctorates". Finally, regarding the research topic, the study explained "most Ph.D. candidates aim to make a significant contribution to knowledge by focusing their efforts on a perceived gap in the literature in a subject discipline. By contrast, most universities offering professional doctorates expect research to be undertaken on a topic that related to a candidate's own field of professional practice in their own working lives" (Bourner, et al. 2001).

\section{The Structure of the Program}

The program at Robert Morris University is designed so that students enrolled in it can complete it within six semesters (or three years). This kind of design is not much different from other doctoral programs. Doctoral programs, in general, list the degree requirements and suggest a sequence for completion. What distinguishes this program is the structure and support mechanism this is inherent to the program design. The structural enforcement mechanisms include a "lock step" cohort approach in which all students admitted at the same time take the same courses together in the same sequence.

Initially, an administrative member of the doctoral staff registers the students for courses each semester. The students do not have a choice among courses nor do they have options in the number of courses. The students must take the 3 specific courses each semester in order to proceed to the next semester. In order to assure that the students take what is required, a doctoral program administrative staff member registers the students. This reduces the possibility of errors. Furthermore, this it facilitates the progression of students from one semester to the next, thus creating an enforcement mechanism for the specified course sequence.

Second, the course content is the same for all the students enrolled in the program. This includes the same textbooks, instructor, materials, assignments, and rigor. This policy helps to eliminate the disparity in course content and results in consistent knowledge base for each student in the cohort.

\section{The Residency Weeks and Weekends}

The doctoral program at this university is conducted during the mandatory scheduled residency period. Each of the six terms has a scheduled residency of 7 days (late August for the fall term and early January for the spring term) and 3 residency weekends each term held at 5 week intervals The students enrolled in the program stay at a nearby hotel with reservations and accompanying logistics taken care of by the RMU staff. The hotel cost, food, and related expenses are integrated into the yearly tuition cost.

The residencies are tightly scheduled with formal classes and one-on-one faculty student meetings. The schedule runs from 8:00 AM to 9:00PM with breaks every hour and a half, time for lunch and dinner. Both class time and break time allow for both formal and informal discussion between faculty and students. Having a dedicated scheduled time for this program helps the students clarify issues regarding the course work and research in the following ways:

1- It helps with student-to-student communications. The students are there all day long and have the time to communicate with others regarding their course work.

2- It helps communicating with faculty also. All faculty members in the program attend the residency week/weekend also. 
3- It may work as a channel to communicate with the administration in this program. The administrators of the program attend the residency week/weekend.

\section{The Cohort Enrollment Approach}

The cohort approach takes a different direction. In this approach, students start the program as one group (cohort), then take courses at the same time and move to complete the program together. Entering a program with a particular group of students, and taking courses with the same students helps to reduce the feeling of isolation. It helps the students to get to know each other, and share experiences among each other. But moreover, the content of the doctoral program at RMU include additional activities that help breaking isolation among the students themselves and also among the students and faculty alike.

1- Study and Discussion: This is an early day informal session that may be held over breakfast, thus is nicknamed the "breakfast club".

2- Community Dinner: This is a meeting/dinner that is sponsored by the program. The dinner is held at the beginning of the semester and is attended by the students from the different cohorts, the faculty and administrators of the programs.

3- Debriefings: These are informal sessions that are held at the end of the day. The debriefing meetings take place to discuss issues brought up during the day.

\section{The Field Project}

The field research project in this program is similar to doing a dissertation in other doctoral programs. Applied research is the focus of each field project. A field research project is developed through the following process:

1- A proposal for the field project must be submitted at the end of the second year and must be defended in front of a selected committee.

2- Following the approval of the proposal, work begins for data collection.

3- The field project must address a problem related to work and the attempts of this field project must be directed toward solving the proposed problem.

4- The student selects a committee that has at least three members. Also, the students are required to include one student from their cohort for reading and feedback.

5- The student is encouraged to select at least one member from the industry for which the project is written for to ensure the practicality of the project.

In support of the field research project are three required seminars. Each seminar is focused on the student field project research. The first seminar is held the second semester of the second year. Its focus is the proposal. The second seminar is third year first semester and it focuses on methodology and data analysis. The final seminar is the third year second semester and it focuses on writing and quality assurance. In each seminar, all the students go through a process of public presentation, defense, and review. The results of such peer evaluation and criticism is a better designed, developed, and written research project.

\section{Summary}

This paper showed common characteristics among some universities that offer doctorate degree programs in the Information Studies/Management Information Systems fields. Among these common characteristics is the emphasis on research of all the programs discussed here and the 
various steps that each program go through including course work, research proposal, selection of faculty and advisor and then working on research project.

At the same time, the paper explained some unique attributes that characterize the doctoral program of Information Systems and Communications at Robert Morris University. These unique attributes of the program are intended to address attrition reasons among doctoral students in general. Although this program only began in 1999, it has so far achieved a significantly higher rate of graduation than the national average. Based on these unique characteristics of this program, it can be said about it that it is "an IS Doctoral Program of a Kind".

\section{References}

Arizona State University. (2003). Persistence, attrition, and graduation rates. Retrieved November 10, 2004 from http://grad.admin.arizona.edu/gcdata/attr

Bourner, T., Bowden, R., \& Laing, S. (2001). Professional doctorates in England. Studies in higher education, 26, 1. Retrieved February 18, 2004 from EBSCOHost.

Carnegie-Mellon University. (2004). Doctoral programs: Degree requirements. Retrieved November 22, 2004 from http://web.tepper.cmu.edu

Drexel University. (2004). PhD program description. Retrieved November 22, 2003 from http://www.cis.drexel.edu/forms/PhDProgramDescription.pdf

Graduate \& Professional Programs: An Overview (2004). Peterson's. Lawrenceville, NJ: Thompson Publishing.

Graduate Programs in Business, Education, Health, Information Studies, Law and Social Work. (2004). Peterson's. Lawrenceville, NJ: Thompson Publishing.

Lehigh University. (2004). Lehigh University graduate study. Retrieved November 22, 2003 from http://www3.lehigh.edu/academics/acgradstudy.asp

Lovitts, B. E (2001). Leaving the ivory tower: The causes and consequences of departure from doctoral study. Lanham, MD: Rowman \& Little Field.

Lovitts, B. E. \& Nelson, C. (2005). The hidden crisis in graduate education: Attrition from Ph.D programs. Retrieved January 27, 2005 from http://www.aaup.org/publications/academe/2000/00nd/ND00LOVI.HTM

National Center for Education Statistics [NCES]. (2003). Digest of education statistics 2002. Washington DC, National Center for Education Statistics.

NationMaster. (2004). Encyclopedia: doctorate. Retrieved 11/15/2004 from http://www.nationmaster.com/encyclopedia/Doctorate

Pennsylvania State University. (2004). IST's Ph.D. rogram - an overview. Retrieved November 22, 2003 from http://www.ist.psu.edu/academics/graduatedisplay

Powers, L. (2004, October 29). Doctoral dilemma: Half of all Ph.D. candidates drop out, wasting resources. Reno Gazette-Journal. Retrieved November 15, 2004 from http://www.rgj.com/news/stories/html/2004/10/29/84016.php.

Robert Morris University. (2004). Doctoral program at a glance. Retrieved November 22, 2004 from http://www.rmu.edu

Temple University. (2004). Temple University graduate school. Retrieved November 22, 2003 from http://mdev.temple.edu/gradschool/common

University of Pennylvania. (2004). PennCIS Doctoral Program. Retrieved November 22, 2003 from http://www.cis.upenn.edu/grad/phd-overview.shtml 
University of Pittsburgh. (2004). Library \& Information Science: Degrees / Doctor of Philosophy (PhD). Retrieved November 22, 2003 from http://www.sis/pit.edu

\section{Biographies}

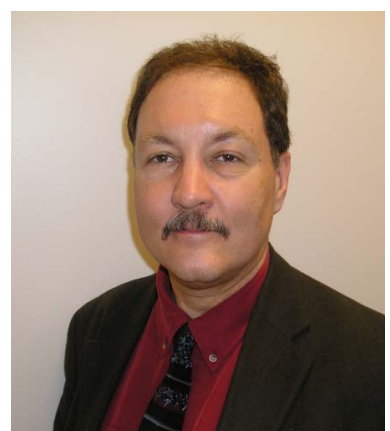

Frederick G. Kohun, Ph.D., Associate Dean and Professor in the School of Communications and Information Systems at Robert Morris University in Pittsburgh, has more that 29 years experience as a professor and administrator in the information systems field. He holds a bachelor degree in economics from Georgetown University, graduate degrees in economics and information science, from the University of Pittsburgh, and a Ph.D. in applied history in technology from Carnegie Mellon University. He had a leadership role in the design and implementation of eight technology based academic programs at the undergraduate and graduate level including a doctoral program. Most recently, he was involved in the first round of ABET-CAC information systems accreditation.

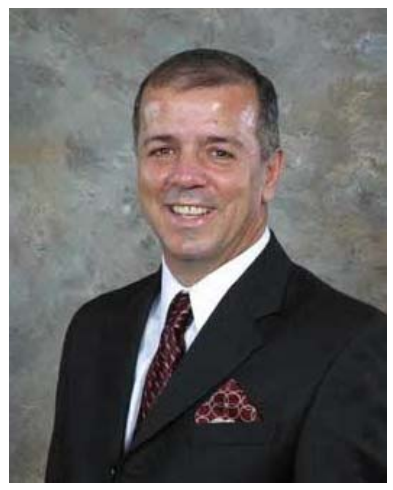

Azad Ali, D.Sc., Associate Professor of Computer Information Systems at Butler County Community College in Butler, Pennsylvania has 22 years of combined experience in areas of financial and information systems. He holds a bachelor degree in Business Administration form the University of Baghdad, an M.B. A. from Indiana University of Pennsylvania, an M.P.A. from the University of Pittsburgh, and a Doctorate of Science in Communications and Information Systems form Robert Morris University. Dr. Ali research interests include object oriented languages, web programming tools, and curriculum design. His community service and academic expertise gets him in the news on Pittsburgh television and in the newspapers. 